\title{
Influence of heat treatment on mechanical properties, microstructure, and fracture surface morphology of $\mathrm{V}-5 \mathrm{Cr}-5 \mathrm{Ti}$ alloy
}

\author{
M. Islam ${ }^{1 *}$, F. Moon' ${ }^{2}$ Heshmat Aglan' ${ }^{1}$ \\ ${ }^{1}$ Tuskegee University, Tuskegee, AL 36088, USA \\ ${ }^{2}$ Louisiana State University, Baton Rouge, LA, 70803, USA
}

\begin{abstract}
Nuclear fusion reactors are becoming an efficient source of energy in next generation energy. The development of structural materials is a foremost step towards building the environmentally friendly reactors. The structural components require superior mechanical and thermal properties to sustain under extreme heat, and radiation fluxes. $\mathrm{V}-5 \mathrm{Cr}-5 \mathrm{Ti}$ alloy is considered as promising structural material for vessel first wall components and blanket applications in fusion reactors due to its high melting point and superior mechanical and thermal properties. In this study, the influence of heat treatment on mechanical properties, microstructural changes, and fracture surface morphology of $\mathrm{V}-5 \mathrm{Cr}-5 \mathrm{Ti}$ alloy were investigated. The result showed that the tensile residual strength was increased by $40 \%$ but the elongation dropped significantly by $67 \%$ after the heat treatment at 650 ${ }^{\circ} \mathrm{C}$ due to dynamic strain aging (DSA) after significant plastic deformation and work hardening. At the higher temperature window from $400{ }^{\circ} \mathrm{C}$ to $700{ }^{\circ} \mathrm{C}$, the diffusion of chromium and titanium possibly facilitate the DSA phenomenon, which enhances the strength at elevated temperatures. The microstructure of the $\mathrm{V}-5 \mathrm{Cr}-5 \mathrm{Ti}$ alloy showed that grain sizes were reduced to $20-60 \mu \mathrm{m}$ after the heat treatment at $650{ }^{\circ} \mathrm{C}$ from the grain sizes of 50 $100 \mu \mathrm{m}$ at room temperature. The fracture surface at room temperature displayed ductile tearing ridges and pulled-up features. After the heat treatment to $650{ }^{\circ} \mathrm{C}$, the sample showed brittle fracture features with intergranular cracks and cleavage facets. The morphological features can be correlated with the mechanical properties to analyze the microstructural origin of strength and toughness of the materials.
\end{abstract}

KEY WORDS: Mechanical properties, Heat treatment, Microstructure, Fracture surface, Morphology, V-5Cr-5Ti alloy

\section{INTRODUCTION}

The materials in nuclear fusion reactors need to withstand extreme temperatures, pressures, neutron doses, radiation fluxes etc. The structural components include first wall, blanket, vacuum chamber, diverter, pressure vessel, condenser, superconducting coils, solenoid, piping, and valves etc., which can be fabricated with different materials. Most common materials used in reactors consist of ferritic/martensitic steels, titanium alloys, austenitic stainless steels, vanadium alloys, tungsten, tantalum alloys, molybdenum alloys, nickel-base super alloys, engineering composites, advanced ceramics, etc. [1, 2, 5]. Among them, vanadiumbased alloys (such as $\mathrm{V}-\mathrm{Cr}-\mathrm{Ti}$ alloy) are considered as promising structural material for fusion reactors for first wall vessel and blanket applications and they can endure high temperature, high pressure, and radiation fluxes. The $\mathrm{V}-\mathrm{Cr}-\mathrm{Ti}$ alloy alloys exhibit better mechanical, physical, and nuclear properties compared to ferritic steel alloys for the fusion environment. These alloys have an excellent thermal conductivity, high strength, good chemical inertness, excellent resistant to radiation, high melting temperature, and low thermal stresses $[3,4,5]$. The nuclear properties assure high neutron wall loading capability and high operating temperature (melting point $1890^{\circ} \mathrm{C}$ ). The $\mathrm{V}-5 \mathrm{Cr}-5 \mathrm{Ti}$ alloy is considered an optimized alloy that exhibits superior creep and fatigue properties. Alloying element titanium improves irradiation-induced swelling and embrittlement resistance with better fabricability, and chromium improves oxidation and creep resistance, neutronic properties, thermal stability, and high heat flux $[3,5,6]$. The effect of temperature on mechanical 
and fracture properties of V-Cr-Ti based alloys have been extensively studied and most cases, it is reported that the mechanical and fracture properties are increased, and elongation is decreased due to hardening phenomenon at temperatures below $700{ }^{\circ} \mathrm{C}$. The mechanical strength of the vanadium alloy at elevated temperatures is also increased by increasing chromium content by reducing interstitial impurities. However, the key concerns for these proposed structural materials that will subject to long term extreme thermomechanical stresses that may cause stress corrosion cracking, high temperature embrittlement, radiation induced defects, and swelling $[5,6,7]$. The rationale behind selecting experimental environmental temperature, $650{ }^{\circ} \mathrm{C}$, was based on actual operating temperatures of first wall and blanket materials in the fusion reactor system, which ranges from $450{ }^{\circ} \mathrm{C}$ to as high as $700{ }^{\circ} \mathrm{C}$ [6]. The upper and lower operating temperature of $\mathrm{V}-5 \mathrm{Cr}-5 \mathrm{Ti}$ alloy are also similar to the actual operating temperature in the fusion reactor and the limits are based on high temperature strength and irradiation embrittlement [5].This work aims to simulate the extreme environment conditions and examine the heat treatment effect on tensile properties, microstructure, and fracture surface morphology of as-received cast and hot forged V-5Cr-5Ti alloy.

\section{MATERIALS AND EXPERIMENTAL}

In this study, the specimens of $2.3 \mathrm{~mm}$ thickness were cut from the $\mathrm{V}-5 \mathrm{Cr}-5 \mathrm{Ti}$ alloy by following sample geometry (Fig. 1). The annealed metal thick sheets were manufactured by Wah Chang Company, Albany, OR. The specimens were exposed to elevated temperature environment before the mechanical testing in order to determine the differences in strength and fracture toughness of the alloys at different environmental conditions. Thus, the base materials were heated in a vacuum oven (Thermo Scientific ${ }^{\mathrm{TM}}$ Lindberg/Blue $\mathrm{M}^{\mathrm{TM}}$ ) at a heating rate of $5^{\circ} \mathrm{C} / \mathrm{min}$ to the temperature of $650{ }^{\circ} \mathrm{C}$ with dwell time of 2 hours, and subsequent cooled down to ambient environment at a rate of $1{ }^{\circ} \mathrm{C} / \mathrm{min}$. The static tensile experiments were performed using a servo hydraulic MTS 810 material testing system. The instrument was facilitated with a load cell of $100 \mathrm{kN}$ and managed with MTS TestStar II software at a controlled displacement of $0.02 \mathrm{~mm} / \mathrm{s}$. Using a computer, force and displacement data were obtained in the real time with the TestStar IIs software. The stress-strain relationship was then developed, from where the yield strength, the ultimate strengths, and the strain to failure were obtained. Static tensile test results of the unnotched specimens were used to calculate the ultimate tensile and yield strength. The test results based on the notched specimens were used to determine the residual strength and the plain stress fracture toughness as outlined in ASTM E399.

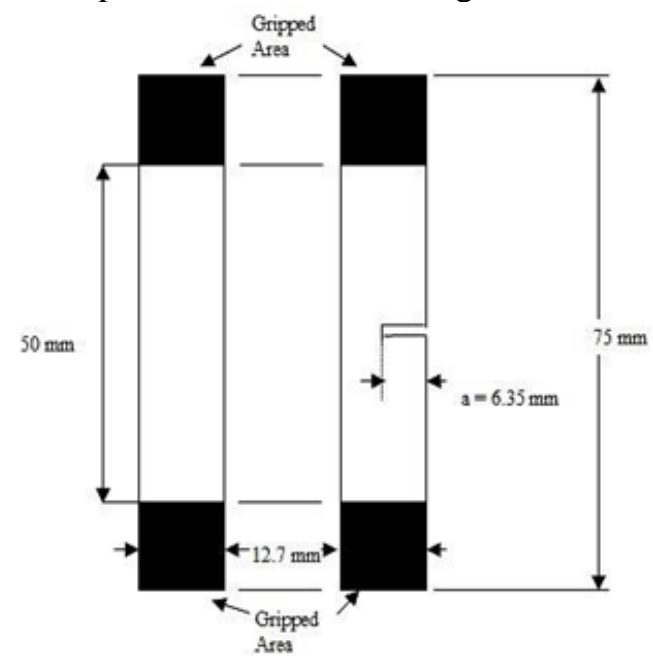

Fig. 1 Specimen geometry for static tensile test specimen, (a) unnotched sample, (b) notched sample.

For optical microstructure studies, the sample from each group was polished and then metallographic etchant (Keller's reagent $95 \%$ DI water, $5 \% \mathrm{HNO}_{3}, 1.5 \% \mathrm{HCl}$, and $1 \% \mathrm{HF}$ ) was used to reveal the microstructures. The optical micrographs were captured with a Paxit digital camera and corresponding software. Scanning electron microscopy (SEM) analyses were performed in order to observe the fracture surface morphology. Specimens were examined after failure under static loadings with a Hitachi S-3400N SEM operated at $15 \mathrm{kV}$ acceleration voltage. 


\section{RESULTS AND DISCUSSION}

Static Tensile Stress-Strain Behavior: The static tensile tests were also performed for both unnotched and single edge notched V-5Cr-5Ti specimens to determine the average ultimate strength, yield strength, and strain to failure at different environmental temperatures of $25^{\circ} \mathrm{C}$ and $650{ }^{\circ} \mathrm{C}$. The tensile stress-strain curve of the alloy for the unnotched specimens as a function of temperature is shown in Fig 1.

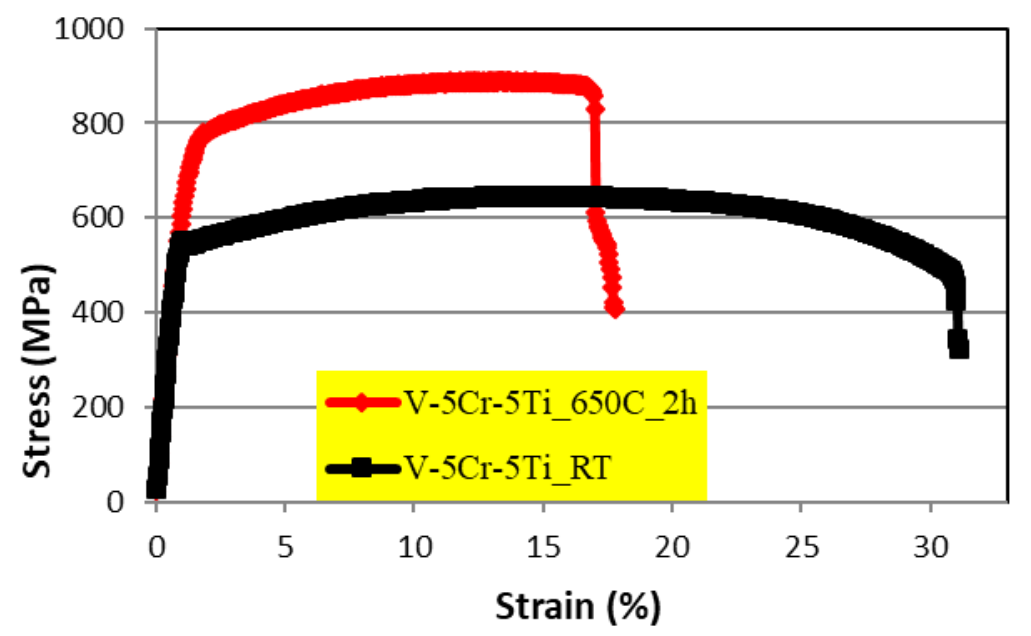

Fig. 1 Tensile strength-strain relationships of V-5Cr-5Ti for unnotched specimens at room temperature and after exposure ( 2 hours) to elevated environmental temperature at $650{ }^{\circ} \mathrm{C}$.

For the unnotched tensile specimens, at room temperature, the average maximum strength of $655 \mathrm{MPa}$, yield strength of $550 \mathrm{MPa}$, and elongation of $29 \%$ was achieved. After $650{ }^{\circ} \mathrm{C}$ exposure for 2 hours, the tensile strength and yield strength increased to $869 \mathrm{MPa}$ and $745 \mathrm{MPa}$, with a 33\%, and 36\% change, respectively. The elongation decreased significantly by a percentage of approximately $45 \%$ (Fig 1). The reason behind the increasing high temperature strength is dynamic strain aging (DSA). At the lower temperature window from room temperature to $400{ }^{\circ} \mathrm{C}$, the diffusion of oxygen and carbon are assumed to be liable for DSA, while at the higher temperature window from $400{ }^{\circ} \mathrm{C}$ to $700{ }^{\circ} \mathrm{C}$, the diffusion of chromium and titanium possibly facilitate to DSA, which enhances the strength at elevated temperatures. This phenomenon has been reported by Kurtz and Takeshi et al. [7, 8].

Fracture Resistance Behavior: The fracture resistance of the specimens was calculated using the maximum stress acquired from the tested notched specimen and is given by following fracture toughness formula as outlined in ASTM E399 [9]. For the single edge notched specimens, the average residual strength of the room temperature and $650^{\circ} \mathrm{C}$ specimens were $320 \mathrm{MPa}$ and $450 \mathrm{MPa}$, respectively (Fig. 2). The tensile residual strength increased by $40 \%$ but the elongation dropped significantly by $67 \%$. The reason for lower elongation value is due to the brittle behavior of the $\mathrm{V}-5 \mathrm{Cr}-5 \mathrm{Ti}$ alloy at elevated temperatures, which can be observed from the fracture surface morphology by using scanning electron microscopy. The average fracture toughness $\left(K_{I}\right)$ value obtained for the room temperature specimens was $39.2 \mathrm{MPa} \sqrt{\mathrm{m}}$, while the average $K_{I}$ value of the $650{ }^{\circ} \mathrm{C}$ specimens was about $51.96 \mathrm{MPa} \vee \mathrm{m}$. There is a $32 \%$ increase from their room temperature values. The calculated value for $K_{I}$ represents plane stress conditions. The detailed data of all tested specimens are given in Table 1. 


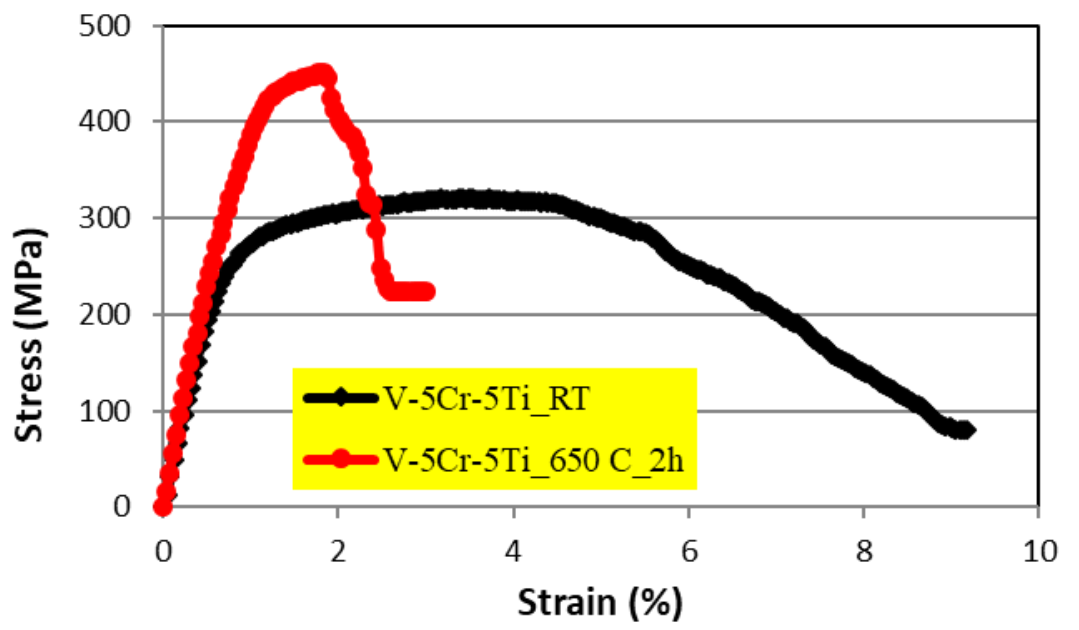

Fig. 2 Residual strength-strain relationships of $\mathrm{V}-5 \mathrm{Cr}-5 \mathrm{Ti}$ for single edge notched specimens at room temperature and after exposure ( 2 hours) to elevated environmental temperature at $650{ }^{\circ} \mathrm{C}$.

Table 1 Average fracture resistance data of $\mathrm{V}-5 \mathrm{Cr}-5 \mathrm{Ti}$ alloy for notched samples at room temperature and $650{ }^{\circ} \mathrm{C}$ samples.

\begin{tabular}{|c|c|c|c|c|c|c|c|c|c|}
\hline Specimen & $\mathrm{W}(\mathrm{mm})$ & $\mathrm{B}(\mathrm{mm})$ & $\begin{array}{c}\mathrm{a} \\
(\mathrm{mm})\end{array}$ & $\mathrm{a} / \mathrm{W}$ & $\mathrm{F}(\mathrm{a} / \mathrm{W})$ & $\mathrm{P}_{\mathrm{m}}(\mathrm{kN})$ & $K_{I}(\mathrm{MPa} \sqrt{\mathrm{m}})$ & $\begin{array}{c}\text { Residual Strength } \\
(\mathrm{MPa})\end{array}$ & $\varepsilon(\%)$ \\
\hline $\mathrm{S}-25^{\circ} \mathrm{C}$ & 12.8 & 2.3 & 6.42 & 0.50 & 2.841 & 9.446 & 39.23 & 320.86 & 9.17 \\
\hline $\mathrm{S}-650^{\circ} \mathrm{C}$ & 12.7 & 2.3 & 6.14 & 0.48 & 2.680 & 12.924 & 51.96 & 450.28 & 3.00 \\
\hline
\end{tabular}

Where, $\mathrm{W}=$ width of specimen; $\mathrm{B}=$ thickness; $\mathrm{a}=$ total crack length; $\varepsilon=$ failure strain; $K_{I}=$ fracture toughness.

Microstructure and fracture surface morphology: The micrograph of the $\mathrm{V}-4 \mathrm{Ti}-5 \mathrm{Cr}$ alloy at room temperature (Fig. 3a) shows a coarse crystal shape structure with a grain size of 50-100 $\mu \mathrm{m}$ and visible distinct grain boundaries. After $650{ }^{\circ} \mathrm{C}$ exposure for 2 hours (Fig. 3b), the grain size becomes smaller compared to the room temperature grain. Some micro grains are also visible after heat treatment. The average grain size reduced to $20-60 \mu \mathrm{m}$ after heat treatment, which may be related to the improved the strength and toughness because of finer grains.
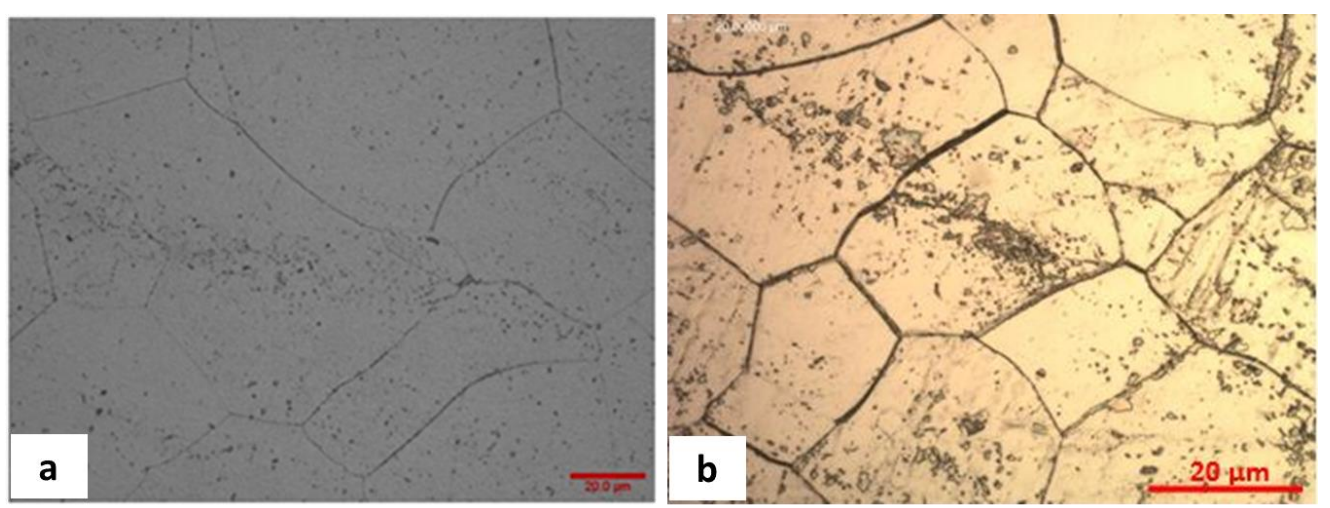

Fig. 3 Microstructural analysis of V-5Cr-5Ti at (a) room temperature and (b) $650{ }^{\circ} \mathrm{C}$ at $50 \mathrm{X}$ magnification.

The fracture surface morphology at room temperature and after $650{ }^{\circ} \mathrm{C}$ exposure for 2 hours is shown in Figures $4 \mathrm{a}$ and $4 \mathrm{~b}$, respectively. It is clearly seen that the fracture surface exhibits ductile pulling features 
with ripping ridges and ripped out strips and demonstrates the plastic deformation. However, the specimen after $650{ }^{\circ} \mathrm{C}$ exposure for 2 hours exhibits some cleavage facets with minor crevices. Thus, the material after the heat treatment at $650{ }^{\circ} \mathrm{C}$ demonstrates more brittle fracture characteristics due to the enhancement of inter-granular fracture by grain boundary precipitates.
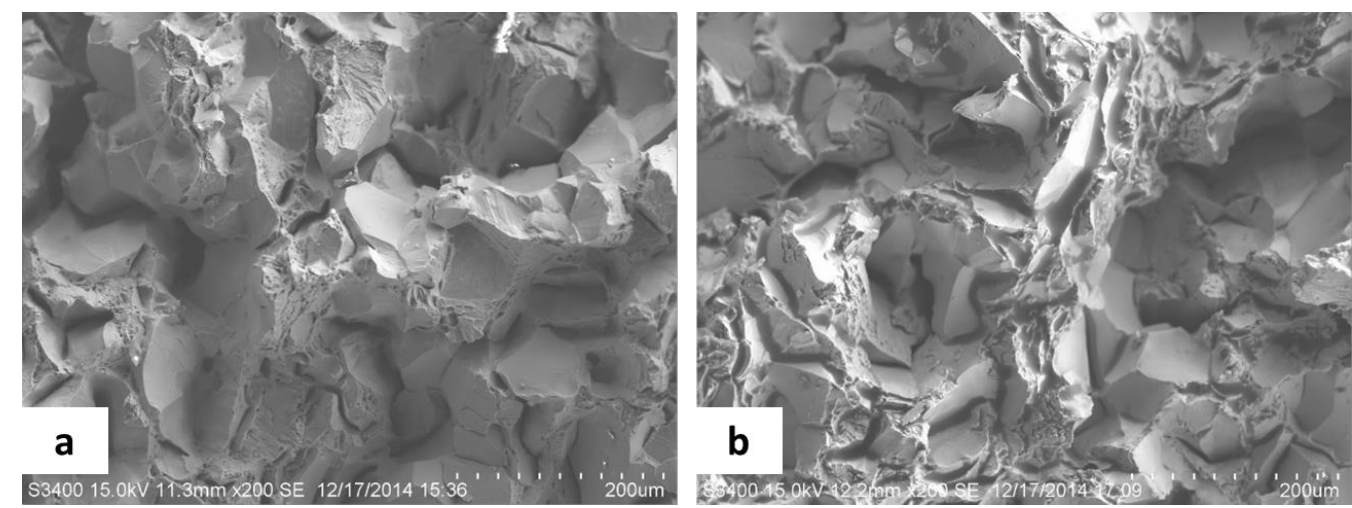

Fig. 4 SEM micrographs of $\mathrm{V}-5 \mathrm{Cr}-5 \mathrm{Ti}$ fracture surface at (a) room temperature and (b) $650{ }^{\circ} \mathrm{C}$ at $200 \mathrm{X}$ magnification.

\section{CONCLUSIONS}

In summary, our study demonstrated that the tensile and fracture properties of $\mathrm{V}$ - 5Cr-5 Ti alloy at elevated temperature increased up to $700{ }^{\circ} \mathrm{C}$ due to significant plastic deformations create heavily stained microstructure and considerable work hardening discloses excellent thermal stability. The diffusion of chromium and titanium may also facilitate the dynamic strain aging (DSA) phenomenon at higher temperatures window from $400{ }^{\circ} \mathrm{C}$ to $700{ }^{\circ} \mathrm{C}$, thus enhancing its strength at high temperatures.

\section{ACKNOWLEDGMENT}

This current work is funded by National Science Foundation (NSF) under the Partnerships for International Research and Education (PIRE) program.

\section{REFERENCES}

[1] Murty, K.L., Charit, I., "Structural materials for Gen-IV nuclear reactors: Challenges and opportunities,” J. Nucl. Mater., 383 pp. 189-195 (2008).

[2] Islam, M., Fermin, C., and Aglan, H., "Microscopic Origin of Strength and Microhardness of Titanium Alloy at Elevated Temperature." Microscopy and Microanalysis, 21, S3, pp. 287-288 (2015).

[3] Aglan, H.A., "Processing orientation - Fracture resistance relationships of V-5Cr-5Ti alloy," Mater. Lett., 62, pp. 865-869 (2008).

[4] Aglan, H.A., Gan, Y., Chin, B., Grossbeck, M., "Fatigue failure analysis of V-4Ti-4Cr alloy,” J. Nucl. Mater. 273, pp. 192202 (1999).

[5] Bloom, E.E. and Smith, D.L., "Structural materials for fusion reactor blanket systems." Journal of Materials for Energy Systems, 7(2), pp.181-192 (1985).

[6] Raole, P.M., Deshpande, S.P. and DEMO Team, "Structural materials for fusion reactors." Transactions of the Indian Institute of Metals, 62(2), pp.105-111 (2009).

[7] Kurtz, R.J., Abe, K., Chernov, V.M., Kazakov, V.A., Lucas, G.E., Matsui, H., "Critical issues and current status of vanadium alloys for fusion energy applications," J. Nucl. Mater., 283, pp. 70-78 (2000).

[8] Miyazawa, T., Muroga, T. and Hishinuma, Y., "Effect of Chromium Content on Mechanical Properties of V-xCr-4Ti-0.15 Y Alloys", J. Plasma Fusion Res., Vol. 11 (2015).

[9] Murakami, Y., "Stress Intensity Factor Handbook," Oxford: Pergamon Press (1990). 